\title{
TGF $\beta$ induces morphological and molecular changes similar to human anterior subcapsular cataract
}

\author{
Frank J Lovicu, Mark W Schulz, Angela M Hales, Lisa N Vincent, Paul A Overbeek, \\ Coral G Chamberlain, John W McAvoy
}

\begin{abstract}
Background: Transforming growth factor $\beta$ (TGF $\beta$ ) has been shown to induce subcapsular plaques in cultured rat lenses as well as in lenses of transgenic mice. In the present study the authors have extended their analysis of these cataract models to determine how closely they mimic human cataract. In particular, they studied the maturation of cataract in the transgenic model to determine if it develops similar features as previously described for anterior subcapsular cataract (ASC) in humans. Furthermore, they investigated whether both of these animal models express the range of molecular markers that have now been shown to be present in human ASC.

Methods: Histology and periodic acid Schiff staining were used to study the development and maturation of subcapsular plaques in transgenic mice overexpressing TGF $\beta 1$ in the lens. Immunolabelling methods were used to identify the molecular markers for ASC in both the transgenic mouse model and in rat lenses cultured with TGF $\beta 2$. Results: Histological analysis showed that the subcapsular plaques that develop in adult transgenic mouse lenses bear a striking similarity to mature human ASC, including the formation of a new epithelial-like layer extending between the subcapsular plaque and the underlying fibre mass. All known molecular markers for human ASC were induced in both rodent models, including collagen types I and III, tenascin, and fibronectin. They also identified the presence of desmin in these plaques, a putative novel marker for human cataract.

Conclusions: In both transgenic mouse and rat lens culture models TGF $\beta$ induces markers similar to those found in human ASC. Atypical expression of these cataract markers is also characteristic of posterior capsular opacification (PCO). The molecular markers expressed are typical of a myofibroblastic/ fibroblastic phenotype and suggest that a common feature of ASC and PCO may be induction of an epithelial-mesenchymal transition by TGF $\beta$.
\end{abstract}

See end of article for authors' affiliations

Correspondence to: Frank J Lovicu, Save Sight Institute and Department of Clinical Ophthalmology and Eye Health, University of Sydney, NSW Australia;

lovicu@anatomy.usyd.edu.au

Accepted for publication 17 September 2001

A nterior subcapsular cataract (ASC) results from aberrant growth and differentiation of lens epithelial cells to form fibrotic plaques that obscure vision. This condition can follow ocular trauma, or eye surgery, or is associated with other diseases (for example, atopic dermatitis ${ }^{1}$ ). In ASC the plaques contain spindle-shaped, "myofibroblast-like" cells and accumulations of a collagenous matrix. ${ }^{23}$ Immunolabelling studies of these cataracts have revealed the presence of cytoskeletal and extracellular matrix proteins not normally expressed by lens cells. Proteins such as $\alpha$-smooth muscle actin, types I and III collagen, fibronectin, and tenascin have all been immunolocalised in the fibrotic plaques of ASC. ${ }^{4-7}$ Another form of cataract that involves aberrant epithelial growth and formation of fibrotic plaques is posterior capsular opacification (PCO; also referred to as secondary cataract or aftercataract) that arises from lens epithelial cells that are left behind following cataract surgery. ${ }^{8}$ In PCO the plaques also contain spindle-shaped cells and express some of the abnormal markers found in ASC..$^{9-11}$

Studies in our laboratory have previously shown that exposing rat lens cells to transforming growth factor $\beta$ (TGF $\beta$ ) induces some of the morphological and molecular changes reported in human ASC. In whole lens cultures, TGF $\beta$ induces the formation of opacities that correspond to distinct subcapsular plaques. ${ }^{12}{ }^{13}$ These plaques are comprised of aberrant spindle-shaped cells together with abnormal deposits of extracellular matrix (ECM). TGF $\beta$ was also shown to induce the expression of both $\alpha$-smooth muscle actin and type I collagen. ${ }^{12}$ In vivo models have confirmed the effects of TGF $\beta$ on lens cells. Srinivasan and co-workers ${ }^{14}$ have shown that ASC can be induced by overexpression of a self activating form of human TGF $\beta 1$ in the lens of transgenic mice. The subcapsular plaques in these mice share some similarities with those induced by TGF $\beta$ in rat lenses in vitro.

These in vitro and in vivo rodent cataract models may therefore be useful for investigating the molecular and cellular basis of ASC in humans. Information from these models may also be relevant to PCO as this form of cataract has many similar features to ASC. In the present study we have extended our analysis of these cataract models. In particular, we have studied the maturation of cataract in the transgenic model to determine if it develops similar features as described for ASC in humans. We also used immunolabelling methods to determine whether the in vitro and in vivo models express the range of molecular markers that have now been identified in human ASC.

\section{MATERIALS AND METHODS}

All experimental procedures conformed to the Association for Research in Vision and Ophthalmology statement for the use of animals in ophthalmic and vision research and were approved by the University of Sydney animal ethics committee.

Abbreviations: ASC, anterior subcapsular cataract; ECM, extracellular matrix; EMT, epithelial mesenchymal transition; PBS, phosphate buffered saline; PCO, posterior capsular opacification; TGF $\beta$, transforming growth factor $\beta$ 


\section{Transgenic mice}

Transgenic mice from families OVE853 and OVE918 (previously described by Srinivasan et $a l^{14}$ ) were used. These transgenic lines express a secreted, self activating form of human TGF $\beta 1$, from the lens fibre specific murine $\alpha A$ crystallin promoter. ${ }^{14}$

\section{Histology}

Ocular tissues for histology were collected from transgenic and wild type mice at postnatal days 14 (P14), 21 (P21), and 140 (P140). Whole eyes were fixed overnight in 10\% neutral buffered formalin, dehydrated, embedded in paraffin and processed for routine histology. For histochemical analysis, 6 $\mu \mathrm{m}$ thick sections were stained with either haematoxylin and eosin or periodic acid Schiff (PAS) reagent. Two to three eyes were processed for each postnatal stage examined.

\section{Antibodies}

For immunolabelling studies, a panel of different rabbit polyclonal antibodies, raised against the following proteins were used: rat collagen types I and III (Chemicon, Temecula, CA, USA); rat fibronectin (Calbiochem, San Diego, CA, USA); human tenascin (Telios Pharmaceuticals, San Diego, CA, USA); and chicken desmin (Sigma, St Louis, MO, USA). A mouse monoclonal $\alpha$-smooth muscle actin antibody (Sigma; clone 1A4) was used for western blotting.

\section{Immunofluorescence}

For immunofluorescence, $6 \mu \mathrm{m}$ thick paraffin sections of P2 1 eyes were hydrated and incubated for 30 minutes in 3\% normal goat serum to reduce non-specific staining. Sections were then incubated overnight at $4^{\circ} \mathrm{C}$ with primary antibodies specific for either type I collagen, type III collagen, fibronectin, tenascin, or desmin. All primary antibodies were diluted 1:100 with phosphate buffered saline (PBS) supplemented with $0.1 \%$ bovine serum albumin (PBS/BSA). Following a brief rinse in PBS, bound primary antibody was visualised using a fluorescein-isothiocyanate (FITC) conjugated secondary antirabbit antibody, diluted 1:50 (Silenus, Hawthorn, Victoria, Australia). All sections were counterstained with 1 $\mathrm{g} / \mathrm{ml}$ bisbenzimide (Hoechst dye, Calbiochem, La Jolla, CA, USA) to label cell nuclei. Sections were then rinsed with PBS, mounted, and examined using fluorescence microscopy. Two immunolabelling runs were carried out for each antigen and each run included sections from two to three different animals. Each run included sections from different control specimens (rat lenses cultured in medium with no TGF $\beta$ and eyes from wild type mice). In each run, sections were included that were incubated with PBS/BSA and/or non-immune serum instead of primary antibody to control for non-specific fluorescence. Specificity for collagen immunohistochemistry had been previously validated ${ }^{12}$ and the specificity of the antibodies for fibronectin, tenascin, and desmin was confirmed by western blotting (see Fig 6).

\section{Induction of cataractous plaques by TGF $\beta$ in vitro}

Lenses were obtained from adult Wistar rats, female unless specified otherwise, and cultured in serum free medium 199 with or without TGFß2 (Genzyme, Cambridge, MA, USA) at a final concentration of $750 \mathrm{pg}$ to $\mathrm{l} \mathrm{ng} / \mathrm{ml}$, as described previously. ${ }^{15}$ Lenses were cultured for up to 7 days, with renewal of medium every 2 days, but without further addition of TGF $\beta$. By the end of the culture period, lenses cultured with TGF $\beta$ developed distinct opacities.

Whole lenses were either fixed and processed for immunofluorescence as described above or subcapsular plaques from these lenses were harvested for SDS-PAGE and western blot analysis. For immunofluorescence, three lenses were processed for each incubation time examined. For western blot analysis, plaques were collected from up to 10 lenses. Fine forceps were used to tear the posterior lens capsule and to gently separate the entire capsule from the lens fibre mass; the epithelial cells and subcapsular plaques remained associated with the anterior capsule during this procedure. The capsule was pinned out flat with the cellular surface uppermost. The exposed plaques were removed using fine forceps, placed in a

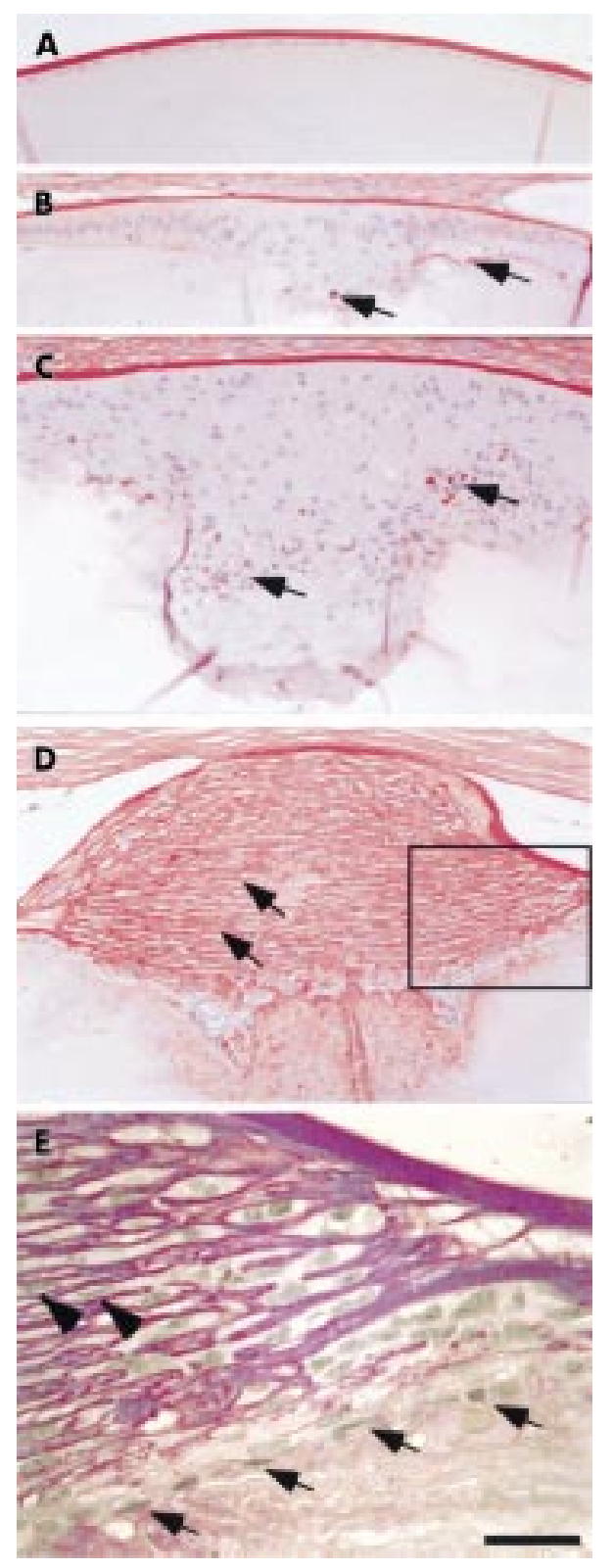

Figure 1 Representative sections of lenses, stained with $\mathrm{PAS}$, from P21 wild type mice (A) and P14 (B), P21 (C), and P140 (D, E) transgenic mice overexpressing TGF $\beta$ in the lens. In the transgenic mice, as early as P14, the central epithelium is multilayered (B) as epithelial cells lose their characteristic cuboidal morphology (see A) and become more elongated. The anterior subcapsular plaques increase in size with age $(B$ and $C$ and $D)$ and demonstrate aberrant deposition of extracellular matrix, evident by PAS staining in red (B, C, arrows). By P140 the mature fibrotic plaque contains laminations of extracellular matrix ( $D$, arrows). In the boxed area in (D), shown at higher magnification in $(E)$, spindle-shaped cells sandwiched between laminae ( $E$, arrowheads) are often oriented parallel to the surface of the plaque. At the inner edge of the plaque a continuous layer of flat epithelial-like cells (E, arrows), often associated with PAS positive basement membrane-like material, separates the fibrous subcapsular plaque from the underlying lens fibre cells. Note that in many cases, as the cornea of transgenic mice develop without endothelial cells, the lens is often attached to the overlying cornea $(B$, C, D). Scale bar (A-D): $100 \mu \mathrm{m}$; (E): $16 \mu \mathrm{m}$. 
fixed volume of ice cold culture medium, and lyophilised. The dry weight of each preparation was determined and corrected for the presence of culture medium.

\section{SDS-PAGE and western blotting}

Lyophilised plaque preparations were dispersed in SDS-PAGE sample buffer (0.06 M TRIS- $\mathrm{HCl}, 30 \%$ (v/v) glycerol, $2 \%$ SDS, $5 \%(\mathrm{v} / \mathrm{v}) \beta$-mercaptoethanol, $0.1 \%(\mathrm{w} / \mathrm{v})$ bromophenol blue, $\mathrm{pH}$ 6.8) at a final concentration of $4 \mu \mathrm{g}$ dry weight $/ \mathrm{ml}$, heated at $100^{\circ} \mathrm{C}$ for 4 minutes, and centrifuged briefly. Equivalent samples of these extracts $(3.5 \mu \mathrm{l})$ were electrophoresed in a 4-15\% gradient gel (Pharmacia, Uppsala, Sweden) using a Pharmacia PhastSystem. Gels were then transferred to PVDF membranes (Millipore, Milford, MA, USA) at $1 \mathrm{~mA} / \mathrm{cm}^{2}$ for 12-14 minutes for western blotting. All membranes were blocked in $2 \%$ non-fat milk powder in PBS $0.5 \%$ Tween 20 (milk-PBS-Tween) for 1 hour at room temperature and all subsequent antibody dilutions and washing were performed using milk-PBS-Tween. Membranes were incubated with primary antibody overnight at $4^{\circ} \mathrm{C}$ using the following antibody dilutions: anti- $\alpha$-smooth muscle actin (1:200); anti-desmin (1:100); anti-tenascin (1:200), and anti-fibronectin (1:200). Membranes were washed three times in milk-PBS-Tween, incubated with a HRP conjugated secondary antibody (Silenus) for 1 hour at $37^{\circ} \mathrm{C}$, washed, and incubated with HRP substrate (diaminobenzidine) for visualisation.

\section{Photography}

Sections were photographed using a Leitz Dialux 20 microscope equipped with normal, dark field and epi-illumination. Immunofluorescence micrographs were captured with 400 ASA film (T-Max, Kodak) pushed to 1600 ASA during processing and bright field micrographs were photographed on 64 ASA film (Ektachrome, Kodak), processed according to manufacturer's instructions. Alternatively, some bright field and dark field micrographs were captured digitally using a Leica DC 100 digital camera (Leica Microscopy Systems Ltd, Heerbrugg, Switzerland).

\section{RESULTS}

\section{Development of ASC induced by TGF $\beta$}

Previous studies have shown that TGF $\beta$ induces anterior subcapsular plaques in cultured rat lenses. ${ }^{12}$ Transgenic mice that overexpress human TGF $\beta 1$ in the lens under the control of the $\alpha$ A-crystallin promoter also undergo plaque development by weanling stage. ${ }^{14}$ While the in vitro model can only be studied for a limited period (approximately 7 days: see Hales et $a l^{12}$ ), the transgenic model has the advantage in that it can be studied throughout the life of the animal. To determine if the transgenic model undergoes the same maturation changes as reported in human ASC, we carried out a developmental study. The normal lens epithelium is a monolayered sheet of cuboidal cells that sits on a thickened basal lamina (the capsule) and faces the lens fibre mass (Fig lA). In the transgenic mice, the monolayer of lens epithelial cells was disrupted by P14, as cells multilayered to form a subcapsular plaque (Fig 1B). The lens cells next to the capsule and either side of the multilayered plaque had already lost their characteristic cuboidal morphology and acquired a more elongated appearance. The lens capsule overlying these aberrant cells appeared thinner, with abnormal deposition of extracellular matrix also found within the fibrotic plaque (Fig 1B, arrows). By P21, consistent with the more prominent cataract observed in mice of this age, there was a marked increase in the size of the plaques (Fig lC). The increase in plaque size reflected an increase in cell number and also an increase in the size of the cells that comprised the plaque. An increased level of aberrant ECM deposition was also noted within these plaques (Fig 1C, arrows), as was the presence of a thin anterior capsule. By P140, a typical pyramidal-shaped plaque tended to bulge out
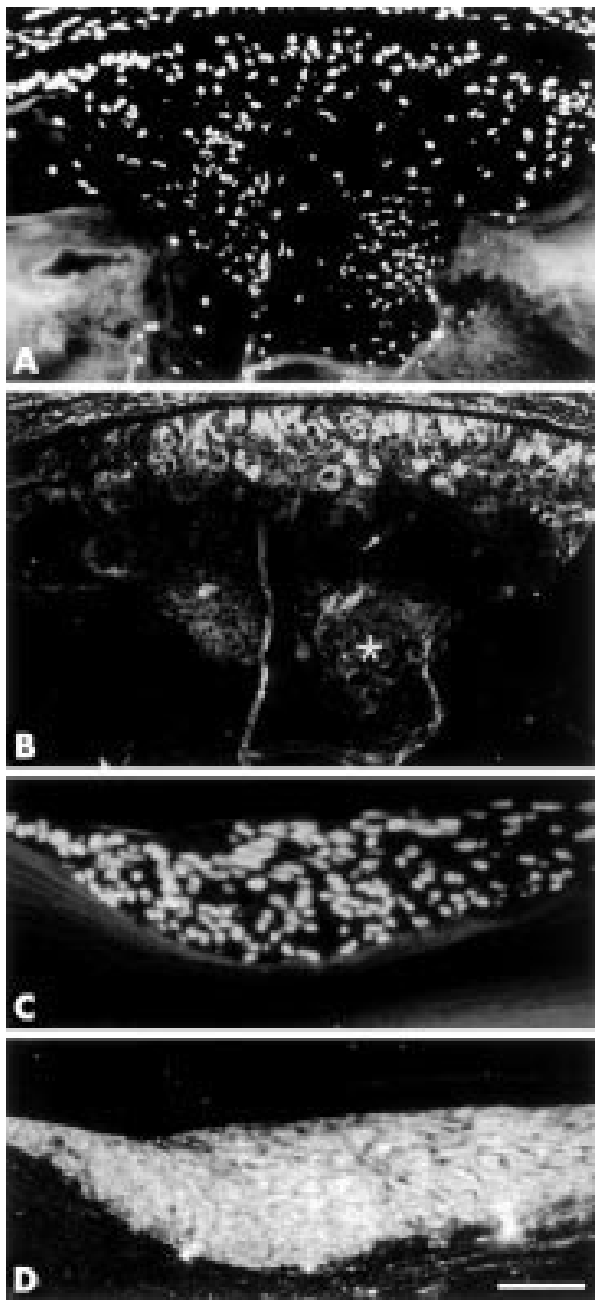

Figure 2 Immunofluorescent localisation of collagen type I (B) and type III (D) in sections of transgenic lenses from P2 1 mice (A, B) or rat lenses cultured for 4 days with TGF $\beta(C, D)$. Sections are counterstained with Hoechst dye $(A, C)$. In lenses of transgenic mice, collagen I is detected in cells closest to the lens capsule (B). Cells deeper in the plaque demonstrate weaker reactivity for collagen type I (asterisk). Plaques from cultured lenses demonstrate strong reactivity for type III collagen (D) throughout the whole subcapsular plaque. Scale bar (A, B): $100 \mu \mathrm{m} ;(C, D): 60 \mu \mathrm{m}$.

from the anterior pole of the lens (Fig ID). Cells of this plaque tended to be spindle-shaped and were often oriented parallel to the surface of the plaque (Fig IE). Frequently two or more cells were in apposition and were surrounded by PAS positive material (Fig lE, arrowheads). At the inner edge of the plaque there was a layer of epithelial-like cells (Fig IE, arrows). These cells, often associated with PAS positive basement membranelike material, separated the fibrous subcapsular plaque from the underlying lens fibre cells (Fig 1D, E).

\section{Immunolocalisation of ASC markers}

In lenses of transgenic mice that overexpress TGF $\beta$ and in rat lenses cultured with TGF $\beta$, we used immunofluorescence to assay for expression of ECM and cytoskeletal proteins that are markers for human cataract.

\section{ECM markers}

Cells in the subcapsular plaques expressed ECM molecules not normally synthesised by lens cells, including types I and III collagen (Fig 2). In lenses of P2 1 transgenic mice reactivity for both these fibrillar collagen proteins was patchy; strongest reactivity was seen in cells close to the lens capsule (see Fig 

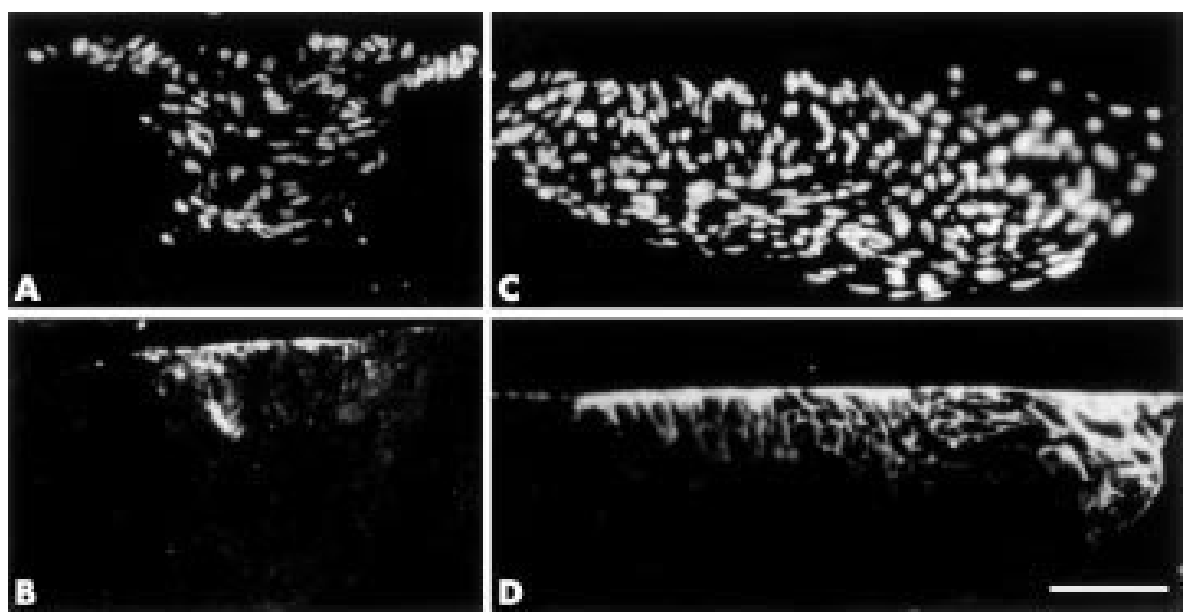

Figure 3 Immunofluorescent localisation of tenascin $(B, D)$ in sections of transgenic lenses from P21 mice $(A, B)$ or rat lenses cultured for 4 days with TGF $\beta(C, D)$. Sections are counterstained with Hoechst dye (A, C). In all plaques, tenascin is predominantly expressed in cells that are closely associated with the lens capsule $(B, D)$. As cells are displaced from the lens capsule, reactivity for tenascin is gradually lost (B, D). Scale bar: $80 \mu \mathrm{m}$.
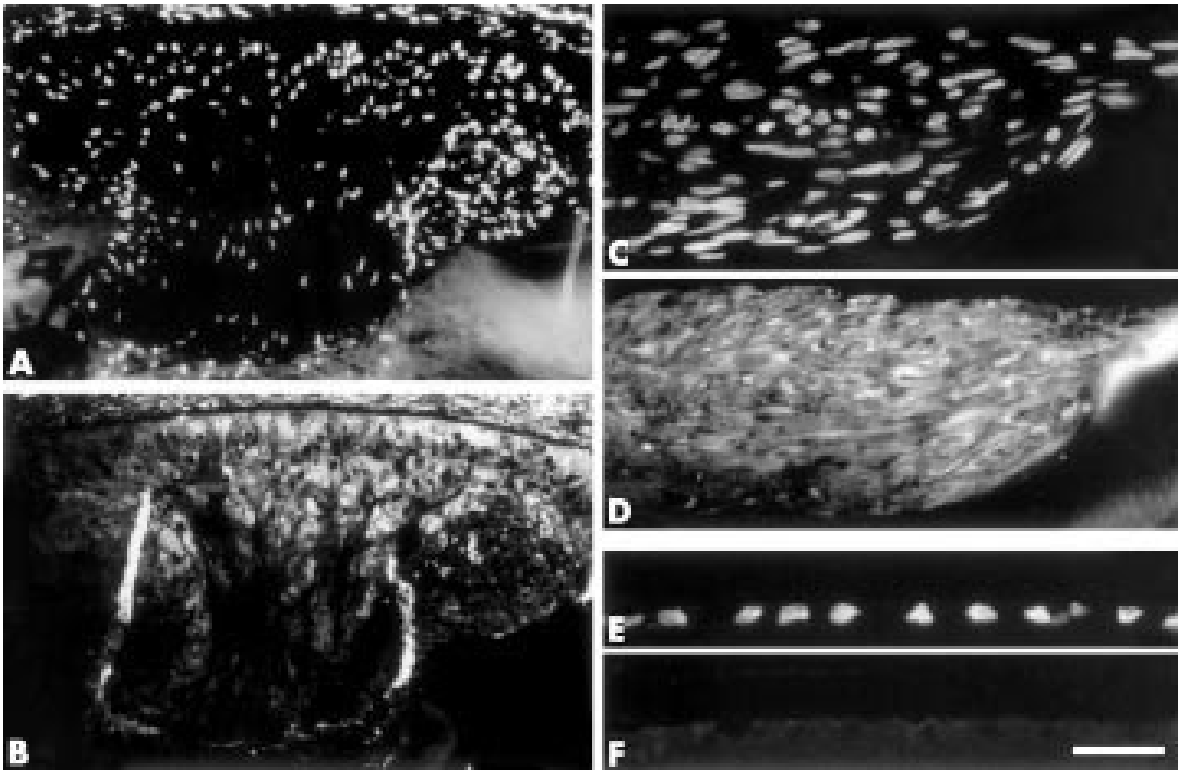

Figure 4 Immunofluorescent localisation of fibronectin $(B, D, F)$ in sections of transgenic lenses from P21 mice $(A, B)$ or rat lenses cultured for 4 days with $(C, D)$ or without $(E, F)$ TGF $\beta$. Sections are counterstained with Hoechst dye $(A, C, E)$. In the subcapsular plaques from transgenic mice and cultured rat lenses, fibronectin is detected in the majority of cells $(B, D)$. The strongest reactivity for fibronectin is seen in cells closest to the lens capsule with cells deeper in the plaque demonstrating weaker reactivity. In control lenses cultured without TGF $\beta$ (F), no fibronectin is detected. Scale bar (A, B): $100 \mu \mathrm{m} ;(C, D): 60 \mu \mathrm{m} ;(E, F): 30 \mu \mathrm{m}$.

2B) whereas cells deeper in the plaques demonstrated weaker reactivity for these collagens. Plaques in whole lenses cultured with TGF $\beta$ also demonstrated reactivity for both type I and III collagen; however, in contrast with the transgenic plaques, strong reactivity was present throughout the whole subcapsular plaque of cultured lenses (see Fig 2D). These collagens were not detected in control lenses cultured without TGF $\beta$ (data not shown).

Tenascin is another ECM molecule that is not normally expressed in the lens; however, it has recently been reported in human cataractous lenses. ${ }^{7}$ In TGF $\beta$ induced plaques, tenascin was expressed specifically in the cells that were adjacent to the lens capsule (Fig 3). This restricted expression pattern was generally similar in plaques derived from both cultured whole lenses and those derived from lenses of transgenic mice. As cells were displaced from the lens capsule, reactivity for tenascin was gradually lost (Fig 3B, D). In the subcapsular plaques derived from transgenic mice lenses, tenascin was detected at P21 but not in older animals indicating a transient expression. In subcapsular plaques from cultured lenses, tenascin expression persisted throughout the 7 day culture period (data not shown).

In subcapsular plaques of lenses of transgenic mice, reactivity for fibronectin was demonstrated in most cells (Fig 4B). Consistent with the collagen labelling, strongest reactivity was generally expressed in cells closest to the lens capsule with cells deeper in the plaque demonstrating weaker reactivity. In lenses cultured with TGF $\beta$, reactivity for fibronectin tended to be strong throughout the plaques (Fig 4D). In control lenses from wild type mice or from rat lenses cultured without TGF $\beta$, no fibronectin reactivity was seen (see Fig $4 \mathrm{~F}$ ).

\section{Cytoskeletal markers}

Previous studies have shown that $\alpha$-smooth muscle actin, a marker for myofibroblasts, is induced by TGF $\beta$ in both in vivo and in vitro models. ${ }^{12}{ }^{14}$ Here we examined the expression of 

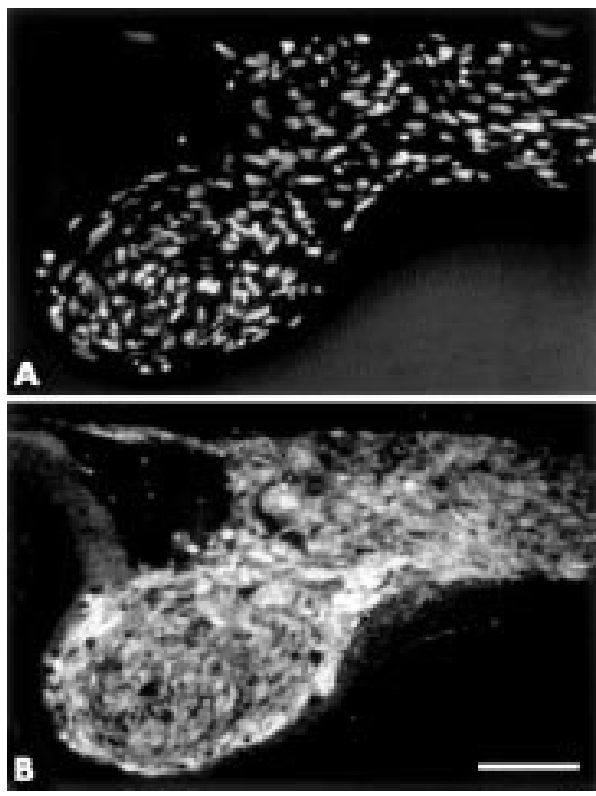

Figure 5 Sections of lenses cultured for 7 days with TGF $\beta$, labelled with Hoechst dye (A) or immunolabelled for desmin (B). Desmin is ubiquitously expressed throughout the TGF $\beta$ induced plaques (B). Scale bar: $60 \mu \mathrm{m}$.

desmin, another cytoskeletal protein characteristic of some myofibroblastic cells. ${ }^{16}$ In plaques of the transgenics and cultured lenses, desmin reactivity was evident, although reactivity tended to be stronger in the plaques of cultured lenses (Fig 5B).

\section{Western blot analysis}

SDS-PAGE and western blotting of protein extracts derived from cataractous plaques from adult male rat lenses cultured with TGF $\beta$, were carried out to confirm that the various antibodies used for immunolocalisation reacted with proteins of the appropriate molecular mass. Consistent with previous immunofluorescence, western blots using a specific antibody for $\alpha$-smooth muscle actin showed a major band at approximately $42 \mathrm{kDa}$ (Fig 6, lane 1). This matches the apparent molecular mass of the microfilament component of $\alpha$-smooth muscle actin as shown by others under comparable experimental conditions. ${ }^{17}$ In western blots probed for desmin, an intermediate filament protein, plaque extracts contained a cross reactive band at approximately $53 \mathrm{kDa}$, the expected

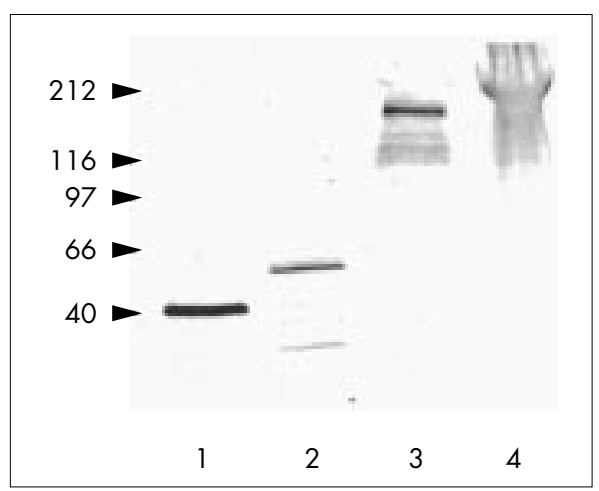

Figure 6 Western blots of extracts from TGF $\beta$ induced cataractous plaques collected from cultured rat lenses probed with antibodies specific to $\alpha$-smooth muscle actin (lane 1), desmin (lane 2), tenascin (lane 3), or fibronectin (lane 4). The position of the bands is consistent with the molecular masses previously reported for each of these proteins. position of the desmin monomer, ${ }^{18}$ with additional bands at lower molecular mass (Fig 6, lane 2). Western blots demonstrated numerous bands for tenascin, with the strongest at approximately $200 \mathrm{kDa}$ (Fig 6, lane 3). Reactivity for fibronectin was also observed as a distinct diffuse band at approximately $230 \mathrm{kDa}$ (Fig 6, lane 4). Negligible reactivity for each of the antibodies was observed using extracts from lenses not cultured with TGF $\beta$, as was the case when non-specific IgG or serum was used in place of the antibodies (data not shown).

\section{DISCUSSION}

In the present study we have further characterised the morphological and molecular changes that contribute to TGF $\beta$ induced cataract formation in cultured whole rat lenses and in transgenic mice. All of the reported morphological and molecular markers for ASC in humans were present in these rodent models of TGF $\beta$ induced cataract. The induction by TGF $\beta$ of the cytoskeletal marker, $\alpha$-smooth muscle actin and of the ECM marker, collagen type I, has been shown previously for rat lens $^{12}{ }^{13} 15$; however, other markers for human ASC, including type III collagen, ${ }^{5}$ tenascin, ${ }^{7}$ and fibronectin ${ }^{6}$ have not previously been reported in these cataract models. Reactivity for tenascin was detected in numerous bands in the western blots. In other tissues, a number of tenascin isoforms have been identified, including tenascin-C, tenascin-R, and tenascin-X. ${ }^{19}{ }^{20}$ On the basis of molecular mass and the restricted tissue distribution of tenascin- $\mathrm{R}$ and tenascin- $\mathrm{X}$, it is most likely that the species present in TGF $\beta$ induced plaques is tenascin-C, although the possibility that it represents an as yet uncharacterised isoform cannot be excluded. Spliced variants of tenascin-C ranging from $190-260 \mathrm{kDa}$ have been reported in the rat. ${ }^{20}$ Fibronectin was detected as a diffuse band in the western blots. This common ECM component typically occurs in a number of different isoforms, with apparent molecular masses of $230 \mathrm{kDa}$ under reducing conditions. ${ }^{21}$ The diffuse appearance of the band indicates that fibronectin in the plaques may be highly glycosylated. In addition, we report for the first time that desmin, also characteristic of myofibroblastic cells, ${ }^{16}$ is induced by TGF $\beta$ in both of the rodent models; thus it may serve as another useful marker for human ASC.

In terms of morphology, this study also showed that the subcapsular plaques that develop in cultured rat lenses and young transgenic mice (P21) resemble early stage human ASC. ${ }^{22}$ However, the advantage of the transgenic model is that cataract development and growth can be studied for the life of the animal. Analysis of the lens at postnatal day 140 (Fig 1D) revealed a striking similarity to mature human ASC, also referred to as anterior polar cataract. ${ }^{23}$ The similarity between the human and mouse model extends from the gross morphology (human ASC being described as "a metaplastic fibrous nodule,"23) through to similar histological features including the presence of numerous layered lamellae of collagen fibres, the sparsely distributed fibroblastic cells wedged between lamellae, and the formation of a layer of epitheliallike cells extending between the plaque cells and the fibre mass. $^{23}{ }^{24}$ This finding, together with support from the lens culture studies, strongly suggests that ASC in humans may arise from increased TGF $\beta$ bioavailability and highlights the need to understand the mechanisms involved in TGF $\beta$ regulation in the eye. This information is fundamental to understanding the molecular aetiology of this cataract and devising strategies for slowing or preventing its onset and progression.

Although the TGF $\beta$ induced subcapsular plaques in transgenic mice (at least at P21) are morphologically similar to those found in cultured whole rat lenses, the position and number of plaques found in these two models differ. In transgenic mice there is a large anterior polar opacity that corresponds to a large subcapsular plaque derived from the 
central lens epithelium as is the case in human ASC (also known as anterior polar cataract because of its location). In contrast, cultured rat lenses contain numerous smaller opacities that correspond to subcapsular plaques that develop at multiple foci ( see Hales et al $^{12}$ ). Interestingly, multifocal plaques have also been reported for anterior subcapsular cataract in the dog. ${ }^{25}$ One possible explanation for the difference between the transgenic mouse model and the cultured rat lens model may relate to the mode of presentation of TGF $\beta$ to the lens epithelial cells. In the former, the lens fibre cells that underlie the epithelium overexpress and secrete TGF $\beta$. In addition, the lens epithelial cells are also exposed to the aqueous humour, which contains molecules that could potentially influence bioavailability of TGF $\beta$ (see Schulz et $a^{26}$ ). Moreover, such molecules may be differentially distributed between the aqueous humour of the anterior and posterior chambers that bathe the central and peripheral lens epithelium, respectively. In the culture model, exogenous TGF $\beta$ added to the culture media is potentially available to all lens cells and this may be reflected in the formation of plaques throughout the epithelial sheet.

The present study shows that the individual plaques that develop in response to TGF $\beta$ in the two models exhibit some differences. For example, the plaques that develop in the transgenic mice appear to be composed of a more heterogeneous population of cells than the plaques that develop in the cultured lenses. This is illustrated by their patterns of ECM reactivity, particularly the collagens and fibronectin (Figs 2 and 4). The transgenic model shows patchy immunoreactivity, with some regions within the plaque being weakly reactive or non-reactive. Regional differences within the plaque indicate that other factors may be involved in regulating their growth and differentiation. This phenomenon may also reflect the fact that in the transgenic mouse lens, in addition to the high level of active TGF $\beta$, cells are exposed to growth factors and other influences present in the ocular media that bathe the lens. The cornea, which is often in contact with the lens (see Fig 1), may also exert an inductive influence. In contrast, in the culture model, the only added factor is TGF $\beta$. While endogenous factors are still likely to be involved in regulating cell behaviour in the cultured lenses, they may not have such a prominent role as in the transgenic mouse, if only by virtue of the presence of the ocular media in the latter. These observations of differences between the two models raise questions for future study.

This study which builds on the results of our previous work, shows that during the development of TGF $\beta$ induced cataract, lens cells undergo a major phenotypic change concomitant with the formation of cataractous plaques. Lens cells are clearly the source of these plaques as there are no other cell types present within the lens and the capsule is an effective barrier to entry of other cells. TGF $\beta$ stimulation induces lens epithelial cells to undergo aberrant growth and differentiation. The cells acquire new patterns of gene expression that are abnormal for lens cells but are markers for myofibroblastic/ fibroblastic cells. These changes are characteristic of an epithelial mesenchymal transition (EMT). EMT is important during embryonic development and also during wound healing responses. TGF $\beta$ has been shown to be an important regulator of these processes in a variety of situations. ${ }^{27}{ }^{28}$ The fact that ASC involves a wound healing-like EMT was first noted by Mattern and co-workers. ${ }^{29}$ Involvement of a wound healing response in ASC is consistent with the various risk factors for this type of cataract, one of the most common being trauma. ${ }^{30}$ PCO is another form of cataract that exhibits features of a wound healing response and involves aberrant epithelial growth. Epithelial cells that are left behind after cataract surgery grow within the capsular bag and undergo various phenotypic changes including myofibroblastic/fibroblastic transition. ${ }^{31}$ The opaque plaques and wrinkling of the lens capsule that results cause opacities which require further treatment in a large proportion of cataract patients. ${ }^{8}$ Work in our laboratory has shown that TGF $\beta$ induces PCO-like pheno- typic changes in lens epithelial explants. ${ }^{26}{ }^{32}$ This indicates that understanding the regulation of aberrant epithelial growth and differentiation by TGF $\beta$ is not only relevant to ASC but also to PCO. The rodent models described in detail in this study will be useful for investigating such aberrant lens epithelial cell growth and differentiation and the mechanisms underlying EMT progression that is a central feature of this lens pathology.

\section{ACKNOWLEDGMENTS}

This study was supported by funding from the NEI (USA); EYO3177 (JMCA), EY10448 (PAO), and from the NHMRC (Australia). JMcA and FJL would also like to acknowledge the support of the Sydney Foundation for Medical Research and the NSW Department of Health.

\section{Authors' affiliations}

F J Lovicu, M W Schulz, A M Hales, L N Vincent, C G Chamberlain, J W McAvoy, Department of Anatomy and Histology and Institute for Biomedical Research, University of Sydney, NSW, Australia

F J Lovicu, A M Hales, J W McAvoy, Save Sight Institute and Department of Clinical Ophthalmology and Eye Health, University of Sydney, NSW, Australia

P A Overbeek, Department of Molecular and Cellular Biology, Baylor College of Medicine, Houston, TX, USA

\section{REFERENCES}

1 Sasaki K, Kojima M, Nakaizumi H, et al. Early lens changes seen in patients with atopic dermatitis applying image analysis processing of Scheimpflug and specular microscopic images. Ophthalmologica 1998:212:88-94.

2 Novotny GE, Pau H. Myofibroblast-like cells in human anterior capsular cataract. Virchows Arch [Pathol? 1984;404:393-401.

3 Pau H, Novotny GE, Arnold G. Ultrastructural investigation of extracellular structures in subcapsular white corrugated cataract (anterior capsular cataract). Graefes Arch Clin Exp Ophthalmol 1985;223:375-413.

4 Schmitt-Graff A, Pau H, Spahr R, et al. Appearance of $\alpha$-smooth muscle actin in human eye lens cells of anterior capsular cataract and in cultured bovine lens-forming cells. Differentiation 1990;43:115-22.

5 Hatae T, Ishibashi T, Yoshitomo F, et al. Immunocytochemistry of type I-IV collagen in human anterior subcapsular cataracts. Graefes Arch Clin Exp Ophthalmol 1993;231:586-90.

6 Lee EH, Joo CK. Role of transforming growth factor-beta in transdifferentiation and fibrosis of lens epithelial cells. Invest Ophthalmol Vis Sci 1999:40:2025-32

7 Wunderlich K, Flammer J, Meyer P. Concurrent expression of human connective tissue growth factor (HCTGF) mRNA and tenascin in human anterior subcapsular cataract and membranes of posterior capsule opacification. Invest Ophthalmol Vis Sci 2000:41:S483

8 Apple DJ. Posterior capsule opacification. Surv Ophthalmol 1992;37:73-116.

9 Frezzotti R, Caporossi A, Mastrangelo D, et al. Pathogenesis of posterior capsular opacification. Part II: Histopathological and in vitro culture findings. J Cataract Refract Surg 1990;16:353-60.

10 Ishibashi T, Hatae T, Inomata H. Collagen types in human posterior capsule opacification. J Cataract Refract Surg 1994;20:643-6.

11 Saika S, Kawashima Y, Miyamoto T, et al. Immunolocalization of prolyl 4 -hydroxylase subunits, $\alpha$-smooth muscle actin, and extracellular matrix components in human lens capsules with lens implants. Exp Eye Res 1998;66:283-94

12 Hales AM, Chamberlain CG, McAvoy JW. Cataract induction in lenses cultured with transforming growth factor- $\beta$. Invest Ophthalmol Vis Sci 1995:36:1709-13

13 Hales AM, Chamberlain CG, Murphy CR, et al. Estrogen protects lenses against cataract induced by transforming growth factor- $\beta$ (TGF $\beta$ ). J Exp Med 1997; 185:273-80

14 Srinivasan Y, Lovicu FJ, Overbeek PA. Lens-specific expression of transforming growth factor $\beta 1$ in transgenic mice causes anterior subcapsular cataracts. J. Clin Invest 1998:101:625-34.

15 Hales AM, Chamberlain CG, McAvoy JW. Susceptibility to TGFbeta2-induced cataract increases with aging in the rat. Invest Ophthalmol Vis Sci 2000;41:3544-51.

16 Sappino AP, Schurch W, Gabbiani G. Differentiation repertoire of fibroblastic cells: Expression of cytoskeletal proteins as a marker of phenotypic modulations. Lab Invest 1990;63:144-61.

17 Theodosis DT, Pierre K, Cadoret MA, et al. Expression of high levels of the extracellular matrix glycoprotein, tenascin-C in the normal adult hypothalamanoneurohypophysial system. J Comp Neurol 1997;379:386-98.

18 Cammarata PR, Cantu-Crouch D, Oakford L, et al. Macromolecular organisation of bovine lens capsule. Tissue Cell 1986;18:83-97.

19 Erickson HP. Tenascin-C, tenascin-R and tenascin-X: a family of talented proteins in search of functions. Curr Opin Cell Biol 1993;5:869-76.

20 Schenk S, Chiquet-Ehrismann R. Tenascins. Methods Enzymol 1994;245:52-61 
21 Yamada KM. Fibronectin and other cell interactive glycoproteins. In: Hay ED, ed. Cell biology of extracellular matrix. 2nd ed. New York: Plenum Press, 1991:111-46.

22 Worgul BV. Lens. In: Jakobiec FA, ed. Ocular anatomy, embryology and teratology. Philadelphia: Harper and Row, 1982:355-89.

23 Margo CE. Disorders of the crystalline lens. In: Sassam JW, ed. Ophthalmic pathology with clinical correlations. Philadelphia: Lippincott-Raven, 1997: 145-55

24 Font RI, Brownstein S. A light and electron microscopic study on anterior subcapsular cataract. Am J Ophthalmol 1974;78:972-84.

25 Colitz CM, Malarkey D, Dykstra M, et al. Histologic and

immunohistochemical characterization of lens capsular plaques in dogs with cataracts. Am J Vet Res 2000;61:139-43.

26 Schulz MW, Chamberlain CG, McAvoy JW. Inhibition of transforming growth factor- $\beta$-induced cataractous changes in lens explants by ocular media and $\alpha 2$-macroglobulin. Invest Ophthalmol Vis Sci 1996;37:1509-19.
27 Heider $\mathrm{KH}$, Beug $\mathrm{H}$. TGFbeta signaling is necessary for carcinoma cell invasiveness and metastasis. Curr Biol 1998;8:1243-52.

28 Sun D, Baur S, Hay ED. Epithelial-mesenchymal transformation is the mechanism for fusion of the craniofacial primordia involved in morphogenesis of the chicken lip. Dev Biol 2000:228.337-49.

29 Mattern RM, Zuk A, Hay ED. Retinoic acid inhibits formation of mesenchyme from lens epithelium in collagen gels. Invest Ophthalmol Vis Sci 1993;34:2526-37.

30 Koch FH, Cusumano A, Seifert, P, et al. Ultrastructure of the anterior lens capsule after vitrectomy with silicone oil injection. Correlation of clinical and morphological features. Doc Ophthalmol 1995-6;91:233-42.

31 Marcantonio JM, Rakic JM, Vrensen GF, et al. Lens cell populations studied in human donor capsular bags with implanted intraocular lenses. Invest Ophthalmol Vis Sci 2000;41:1130-41.

32 Liu J, Hales AM, Chamberlain CG, et al. Induction of cataract-like changes in rat lens epithelial explants by transforming growth factor- $\beta$. Invest Ophthalmol Vis Sci 1994;35:388-401. 